\title{
A Study on Unsteady Flow Phenomena at Near-Stall in a Multi-Stage Axial Flow Compressor by Large-Scale DES with K Computer
}

\author{
${ }^{1}$ Department of Mechanical Engineering, Kyushu University \\ 744 Motooka, Nishi-ku, Fukuoka 819-0395, Japan \\ ${ }^{2}$ Kawasaki Heavy Industries, Ltd. \\ 1-1, Kawasaki-cho, Akashi, Hyogo 673-8666, Japan
}

Kazutoyo Yamada ${ }^{1}$, Masato Furukawa ${ }^{1}$, Satoshi Nakakido ${ }^{1}$, Yuki Tamura ${ }^{1}$, Akinori Matsuoka ${ }^{2}$ and Kentaro Nakayama ${ }^{2}$

\begin{abstract}
The paper presents the results of large-scale numerical simulations which were conducted for better understanding of unsteady flow phenomena in a multi-stage axial flow compressor at near-stall condition. The compressor is a test rig compressor which was used for development of the industrial gas turbine, Kawasaki L30A. The compressor consists of 14 stages, the front two stages and the front half stages of which were investigated in the present study. According to the test data, it is considered that the 2 nd stage and the 5 th or 6th stage are suspected of leading to the stall. The final goal of this study is to elucidate the flow mechanism of the rotating stall inception in the multi-stage axial compressor for actual gas turbines.

In order to capture precise flow physics in the compressor, a computational mesh for the simulation was generated to have at least several million cells per passage, which amounted to 650 million cells for the front 2-stage simulation and two billion cells for the front 7-stage simulation (three hundred million cells for each stage). Since these were still not enough for the large-eddy simulation (LES), the detached-eddy simulation (DES) was employed, which can calculate flow fields except near-wall region by LES. The required computational resources were quite large for such simulations, so the computations were conducted on the $\mathrm{K}$ computer (RIKEN AICS in Japan).

Unsteady flow phenomena in the present compressor at near-stall condition were analyzed by using data mining techniques such as vortex identification and limiting streamline drawing with the LIC (line integral convolution) method. The simulation showed that the stall in the present compressor could be related to the corner separation on the hub side.
\end{abstract}

\section{INTRODUCTION}

The lower limit of the operating range of compressors is determined by the surge, which is an unstable phenomenon of flow. The surge is sometimes provoked by another unsteady flow phenomenon: the rotating stall. The rotating stall poses efficiency degradation, noise generation and blade vibration, at worst which could lead to breakdown of the compressor. Therefore, it is critical to predict the condition of stall inception for design as well as development of compressors. After many researches addressing the issue of the rotating stall, it has been revealed that the disturbance appears as a sign of the rotating stall, and is categorized into two types in axial compressors: the spike-type (short length-scale disturbance) and the modal-type (long length-scale disturbance)[1-3]. The spike disturbance occurs at the stall inception, and rapidly develops into the rotating stall, which is often finished within several

Presented at International Gas Turbine Congress 2015 Tokyo

November 15-20, Tokyo, Japan

Review Completed on August 10, 2016 rotor revolutions. Generally, it would be too late to control the stall even if detecting the spike disturbance. It follows that the better understanding of the flow physics behind the spike-type stall inception is more important, because it allows predicting and improving the stall margin in design stage.

It is widely accepted that the tip clearance flow has a great influence on the compressor stability. Also from the aspect of accessibility in measurements, the tip clearance flow has been investigated. Hoying et al. have explained about the flow field at the stall inception from the numerical simulation, and described the phenomenon that the tip clearance vortex is pushed upstream from the rotor with increasing incidence [4]. Vo et al. have proposed the flow phenomenon called "spillage", which indicates that the tip clearance flow spills into the next passage ahead of the next blade leadingedge below the tip, as criteria for the spike stall [5]. Meanwhile, it is also considered that the spike disturbance is related to a local separation of the boundary layer on the blade suction surface near the rotor tip [6]. The spike stall has been identified as propagating low-pressure regions on the casing wall around the leadingedge $[7,8]$, and it was confirmed that the low-pressure regions have already appeared as the pre-stall disturbance, forming in the forward part of the blade passage [9]. Recently, it has been revealed that the tornado-like radial vortex (Figure 1), which results from the leading-edge separation near the tip, generates the low-pressure region, and its propagation leads to the spike disturbance [10-12]. Moreover, it was explained that the tornado vortex carries the tip clearance flow to the upstream of the rotor, which results in the spillage [12]. In most cases, those findings are from researches for single stage and/or low speed compressors. It is unknown whether they are applicable for actual multi-stage machines, which include unclear effects such as wake interaction and Mach number.

The final goal is to clarify the flow mechanism of the rotating stall inception in an actual axial compressor, conducting a large-scale full annulus simulation of a 14-stage compressor (which include inlet guide vane and outlet guide vane). In the present study, as described hereinbelow, two kinds of simulations that are front 2stage simulation and front 7 -stage simulation have been conducted based on the experimental results.

\section{MULTI-STAGE AXIAL FLOW COMPRESSOR}

The compressor analyzed in this study is a multi-stage axial compressor developed for a 30MW-class high-efficiency industrial gas turbine in Kawasaki Heavy Industries, Ltd.[13]. Figure 2 shows an overview of the gas turbine and its compressor rotor. The compressor consists of 14 stages. In order to achieve a high cycle efficiency, 


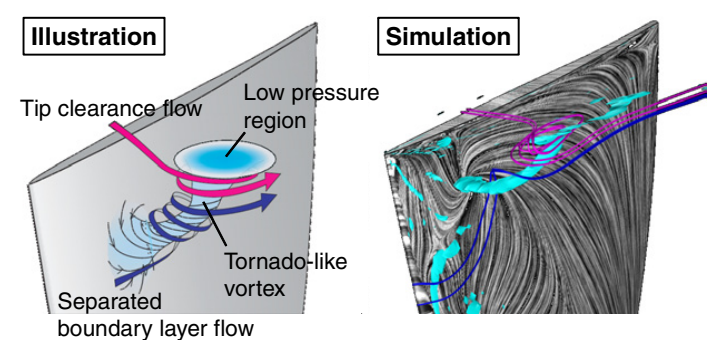

Fig.1 Tornado-like separation vortex at the spike stall inception

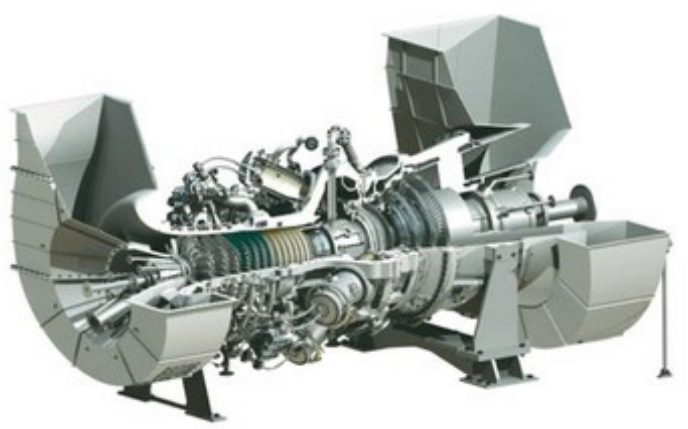

(a) Overview

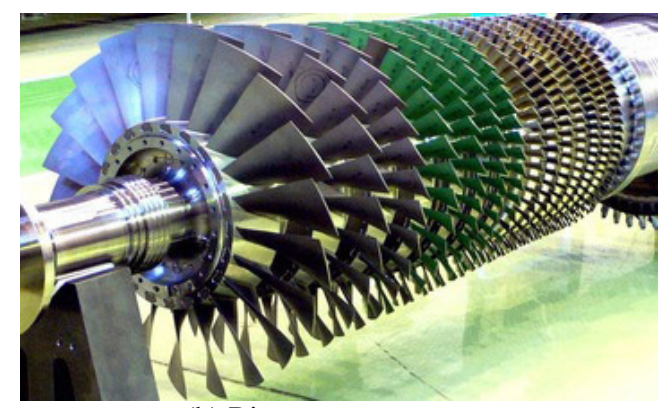

(b) Rig compressor rotor

Fig.2 30MW class gas turbine

Table 1 Specifications of test compressor

\begin{tabular}{ll}
\hline Tip radius of 1st rotor at leading-edge & $272 \mathrm{~mm}$ \\
Tip clearance of 1st rotor & $0.3 \mathrm{~mm}$ \\
Aspect ratio (rotor, stator) & $1.4 \sim 1.1,2.9 \sim 1.1$ \\
Drive shaft speed & $14,810 \mathrm{rpm}$ \\
Mass flow rate & $33.7 \mathrm{~kg} / \mathrm{s}$ \\
Total pressure ratio (14stages) & 22 \\
\hline
\end{tabular}

the compressor has been designed with the pressure ratio of 24 at the design point, which is one of the highest pressure ratios in the middle class gas turbine. The compressor rig test were conducted using a down-scaled compressor in the development of the gas turbine. In this study, the simulations have been conducted for this test-rig compressor instead of the actual one in order to compare the results with the measurement data in the rig test. The specifications of the test rig compressor are given in Table 1.

In the rig test, measurements have been conducted to understand the internal flow condition as well as the overall aerodynamic performance of the compressor. To assess the stage matching during operation, total pressure and total temperature have been measured by the leading-edge sensors mounted on the stator vanes at several stations, and moreover static pressure on the casing wall has been measured at all stations between blade rows. In addition, for the purpose of monitoring the occurrence of the surge or the rotating stall, Kulite sensors have been mounted on the casing wall at the inlet and the exit of the 1st stage and at the exits of the 6th rotor and the 14th rotor, measuring pressure fluctuations. Furthermore, measurements of internal flow fields have been conducted at the upstream and the downstream of the 1st rotor by traversing the threehole probe and the total temperature probe.

\section{NUMERICAL METHOD \\ Flow Solver}

The present simulations were conducted using the in-house code that had been successfully developed by the authors $[14,15]$ and well validated for various turbomachinery flows. The code solves the three-dimensional compressible Navier-Stokes equations by using a fully-implicit scheme with a cell-centered finite volume method. The numerical schemes of the code are outlined in the following. The inviscid flux is evaluated by the Simple Highresolution Upwind Scheme (SHUS) [16], which is extended up to third-order accuracy by the MUSCL interpolation with the Van Albada limiter [17]. The viscous flux is determined in a central differencing manner with Gauss's theorem. The point relaxation method based on MFGS (Matrix Free Gauss-Seidel) implicit algorithm [18] is used for the time integration. To obtain a time-accurate solution, the second-order backward difference is applied to the temporal derivative and the inner iteration is conducted at each time step. In this study, we set the inner iteration to 5 times. A nondimensional time step size, which was normalized by the rotor tip radius and the inlet sound speed, was set to 0.000521 . It follows that the time period of one rotor revolution is resolved with 10,000 time steps.

In this study, the DES approach was employed for the turbulence modeling. The DES in the present study is formulated based on the low Reynolds number $k$ - $\omega$ turbulence model [19]. The dissipation term in the $k$-equation of the $k$ - $\omega$ turbulence model is modified as follows [20]:

$$
\begin{aligned}
& D_{\mathrm{DES}}^{k}=\rho k^{3 / 2} / \tilde{l} \\
& \tilde{l}=\min \left(l_{k-\omega}, C_{\mathrm{DES}} \Delta\right)
\end{aligned}
$$

where $l$ is the turbulent length scale, $\Delta$ is the local grid spacing, and $C_{\mathrm{DES}}$ is a calibration constant of the DES formulation, which was set to 1.60 in this study. The $C_{\mathrm{DES}}$ was calibrated by another test simulation. In order to capture the unsteady phenomena associated with the stall in the tip clearance flow field, the DDES model has not been used in the present study. The tip clearance flow is generally immersed in the thick casing boundary layer, which leads to a problem that the tip clearance flow is calculated by RANS if the DDES model is applied.

\section{Computational Grid}

As mentioned above, off-design flow fields were analyzed for the front two stages (Inlet to the 2nd stator) and the front half stages (Inlet to the 7th stator) of the compressor by the full annulus simulations, respectively. Figure 3 shows the computational grid for the front 7-stage simulation. For the whole computational domain including tip clearance region, the mesh was generated with the multi-block structured grid using AutoGrid5 ver.9.10 (NUMECA International), and the HJO-type grid was used for the mesh topology. As shown in the figure, hub cavities between bladerows are neglected, but partial clearances for the stators and filets of blade root are faithfully modeled.

In order to capture precise flow physics in the stall inception with the DES, at least several million cells are required for each passage. More mesh cells are required in the LES. In addition, there are quite large number of blade passages, which are 670 passages, even in up to the front 7 stages, so that the K computer (RIKEN AICS in Japan) was used for the present simulation. Considering the computational resource, a hundred and several tens million cells were assigned to each blade row. It follows that each passage has several million cells. The grid has 168 cells in the passage height from the hub to the casing, and 37 cells of them are included in the tip clearance zone. The grid is still too coarse to capture a critical state of turbulent boundary layer prior to separation by the LES, so the DES was 


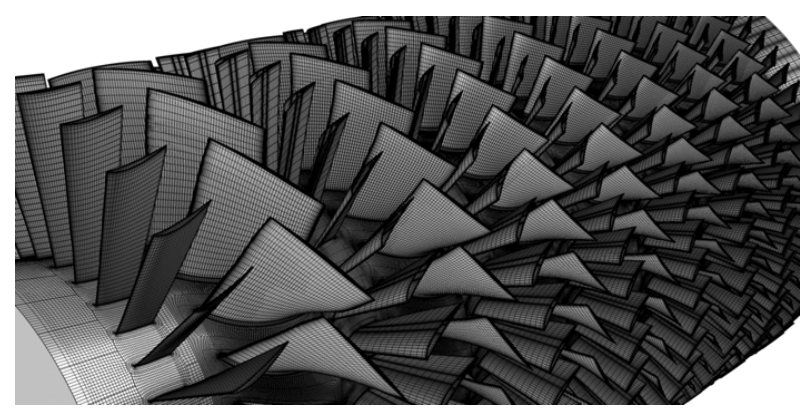

(a) Overview (every three lines)

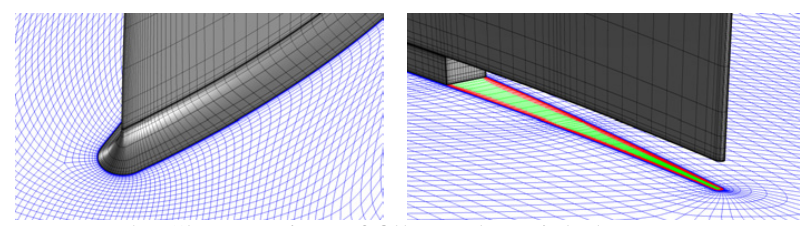

(b) Closeup view of fillet and partial clearance

Fig.3 Computational grid

applied in the present study as stated before. The number of computational cells for the front 7-stage simulation amounts to about two billion in total (650 million for the front 2-stage simulation). The minimum spacing on the wall was set small enough to satisfy with the condition of $y^{+}<1$, so as to evaluate the viscous flux at the wall without the wall function method.

\section{Boundary Conditions}

In the flow solver, fictitious cells are introduced just outside all the boundaries of computational domain, in which the conserved variables are given so as to meet the boundary condition. As the inflow boundary condition, total pressure, total temperature and flow angles in tangential and radial directions are specified, and the conserved variables in the fictitious cells are calculated based on those fixed values. At the outflow boundary, a mass flow rate is specified for accelarating the simulation by starting from the steady-state RANS simulation result. All conserved variables for the fictitious cells are extrapolated from the interior cells, scaling the velocity magnitude so as to maintain the imposed total mass flow rate. In the front 7-stage simulation, instead a static pressure is specified, because there are large discrepancies in the flow field and the stall point from the steady-state simulation. For the fictitious cells next to solid wall boundaries, the conserved variables are given so that no-slip and adiabatic conditions can be satisfied. As for the casing wall boundary, however, the isothermal condition is applied to fix the temperature with the value estimated from the test result. Since temperature of fluids increases in the axial direction in highpressure multi-stage compressors, heat transfer can no longer be neglected especially at near-stall [21]. The mixing plane approach is used for the steady-state RANS simulation, whose results are utilized as the intial condition for the full annulus DES calculations. In the DES calculation, the flow field goes into a quasi-steady state in a couple of revolutions after starting this initial condition.

\section{RESULTS AND DISCUSSIONS}

\section{PERFORMANCE CHARACTERISTICS}

Figure 4 shows an experimental result on characteristics of wall static pressure rise in each blade row. The delta of the wall static pressure rise is defined as the difference from its value at the previous operating point and it is normalized by the delta of the total pressure ratio in the full 14-stage compressor. The abscissa is the total pressure ratio normalized by its value at the surge point. As for the stator, the latter stators of 5th, 6th and 7th take negative value contrary to the other stators as approaching to the surge point, and

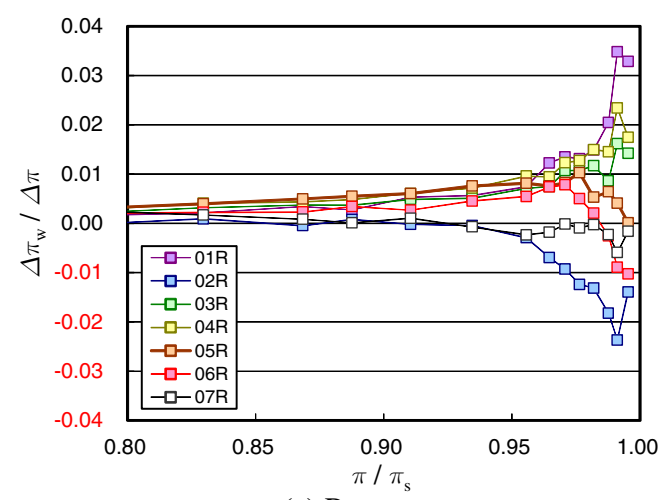

(a) Rotor

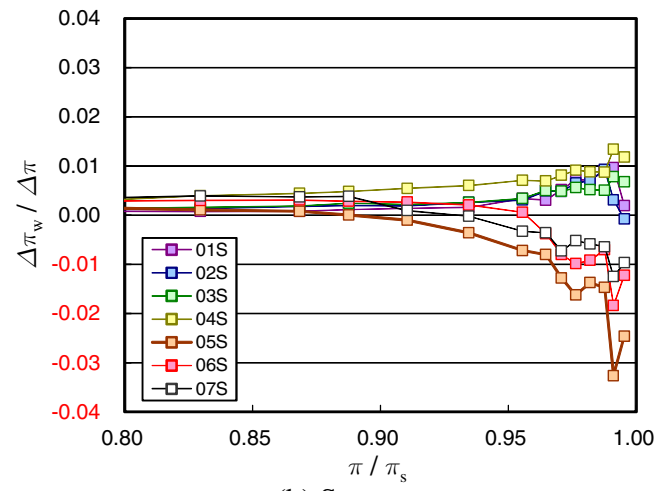

(b) Stator

Fig.4 Pressure rise characteristic for each bladerow

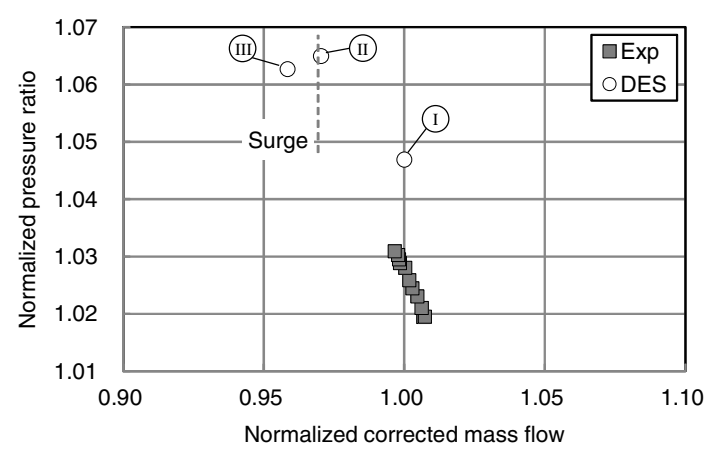

(a) Inlet - 2nd rotor

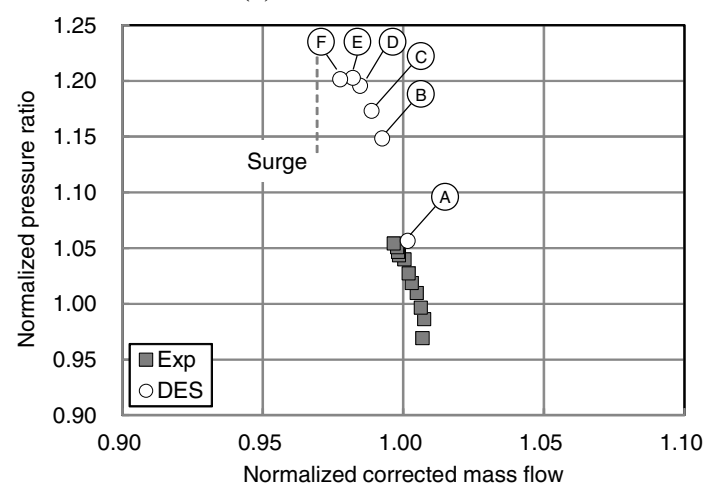

(b) Inlet - 7th rotor

Fig.5 Performance characteristics (gray dashed lines: surge limits for full 14-stage compressor)

the 5th stator is the worst. In the rotors, the performance of the wall static pressure rise deteriorates in the 2 nd rotor. Also, the 5 th rotor and the 6 th rotor present negative gradient near the surge. In this way, the 5th, 6th stator or the 2nd rotor is suspected of provoking the stall in the compressor. Based on this result, two types of simulations were conducted in this study. One is a front 2 -stage sim- 


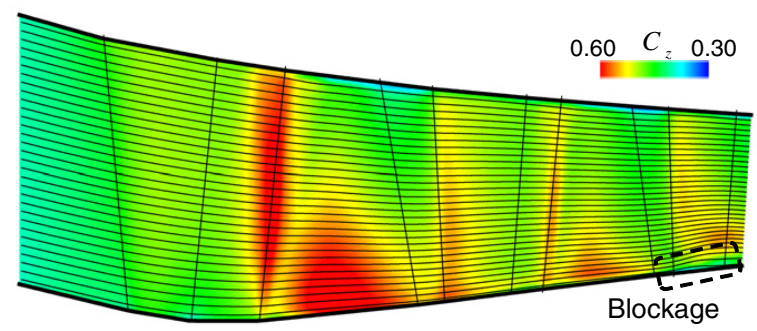

Fig.6 Pitchwise-averaged axial velocity distribution on meridional plane (Front 2-stage simulation, Point II)

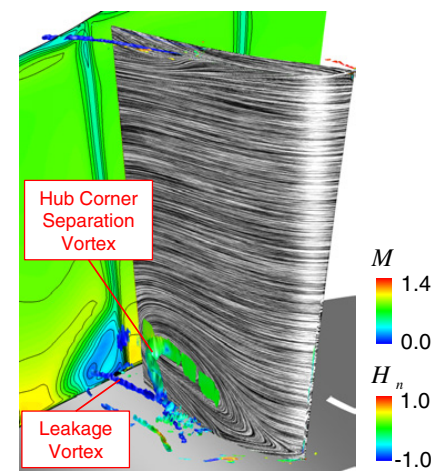

Fig.7 Instantaneous flow field of 2nd stator (Front 2-stage simulation, Point II)

ulation from inlet to the 2nd stator, and the other is a front 7-stage simulation from inlet to the 7 th stator.

Figure 5 shows the performance maps for the front 2-stage and the front 7-stage of the compressor. The pressure ratio of the experiment was obtained from the measurement data of the leading-edge sensors mounted on the stator vanes. In the figure, the pressure ratio and the mass flow are normalized by the respective design values. The gray dashed lines denote a predicted surge limit for the full 14-stage compressor. The simulations were conducted at $100 \%$ speed. The nondimensional mass flow conditions analyzed by the front 2-stage simulation were 1.0 (Point I: design point), 0.97 (Point II: surge point in the experiment) and 0.96 (Point III: stall point in the simulation). The front 7-stage simulations were conducted at six operating points from near-design point (Point A: 1.00) to stall point (Point F: 0.977), increasing the outlet pressure little by little. Both front 2-stage and 7-stage simulations have slightly overpredicted the pressure ratio compared to the experimental results, but their discrepancies are small with less than two percentage points. Comparing the stall point, the stall has started at higher mass flow in the front 7 -stage simulation. It implies that a latter stage has fallen into a stall state prior to the 2nd stage.

\section{FRONT 2-STAGE SIMULATION}

In this section, unsteady flow phenomena at the stall inception, which were confirmed in the front 2-stage simulation, are described.

Figure 6 shows pitchwise-averaged axial velocity distribution on a meridional plane at Point II. There is no low velocity region near the casing wall. Instead, it has appeared on the hub side in the 2nd stator. Figure 7 illustrates a flow field around the 2 nd stator at point II. The figure shows an instantaneous flow field around a representative 2 nd stator vane. Vortex cores colored with the normalized helicity, limiting streamlines on the blade suction surface and a Mach number contour on the crossflow plane just downstream of the stator are described. As seen from the limiting streamlines and vortex cores, the corner separation has occurred on the hub side. This hub corner separation can be found in all 2nd stator vanes at this operating condition. As a result, the low velocity region is seen on the hub side in the 2nd stator, as shown in Figure 6.

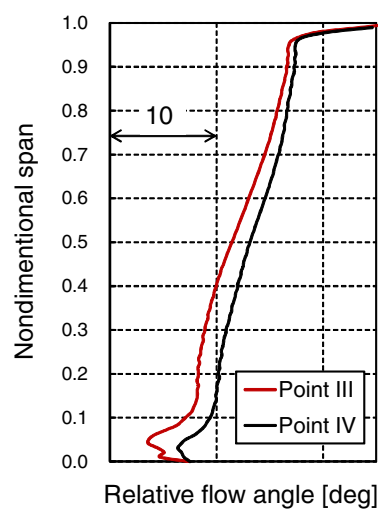

(a) 2 nd rotor

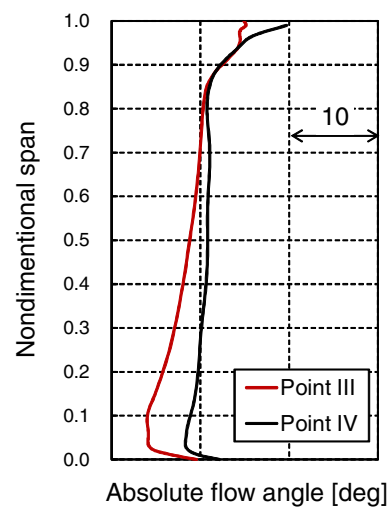

(b) 2nd stator
Fig. 8 Inlet flow angle distributions of 2 nd rotor and stator (Front 2-stage simulation, Point II)
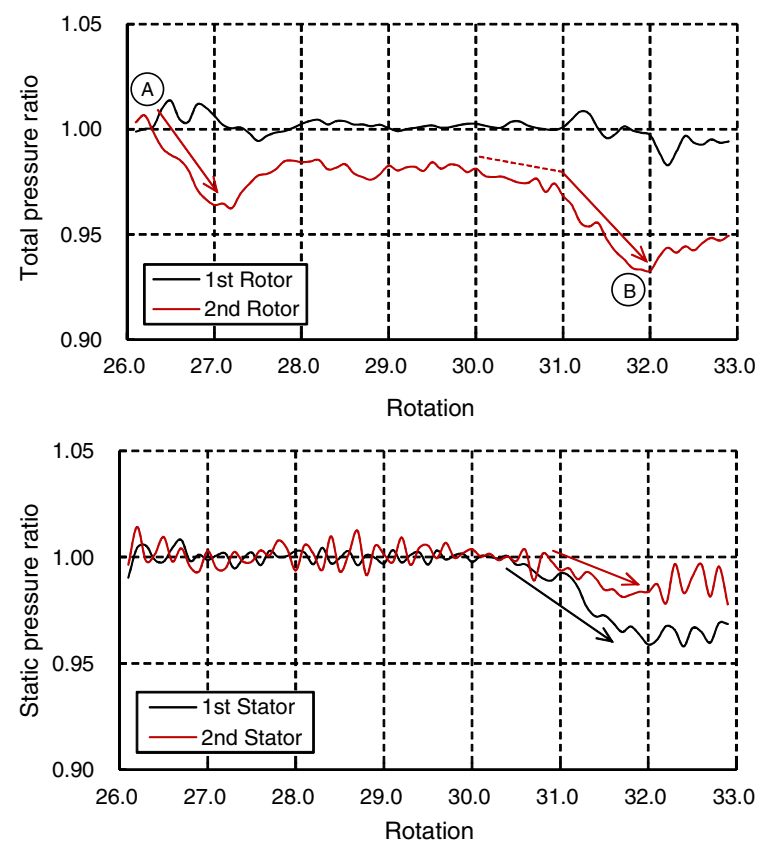

Fig.9 Time histories of pressure ratio at stall inception (Front 2stage simulation, Point III)

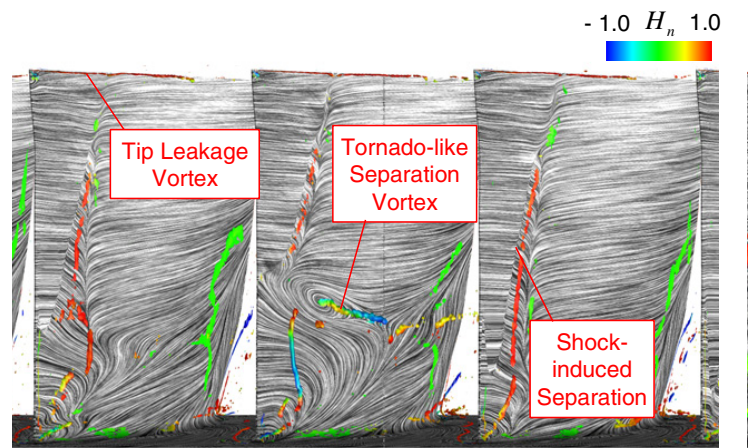

Fig.10 Instantaneous vortical flow structures in 2nd rotor at stall inception (Front 2-stage simulation, Point III)

Figure 8 shows the inlet flow angle distributions of the 2nd rotor and the 2 nd stator. In the figure, the flow angle represents the relative flow angle for the rotor and the absolute flow angle for the stator. As seen in the figure, the flow angle is increased on the hub side with decreasing flow rate. As mentioned above, the hub corner separation arises in the 2nd stator at point II, and thereby it generates a large blockage on the hub side. The increase of the flow angle on the hub side is caused by this blockage effect due to the hub corner separation. In addition, the influence of the blockage 


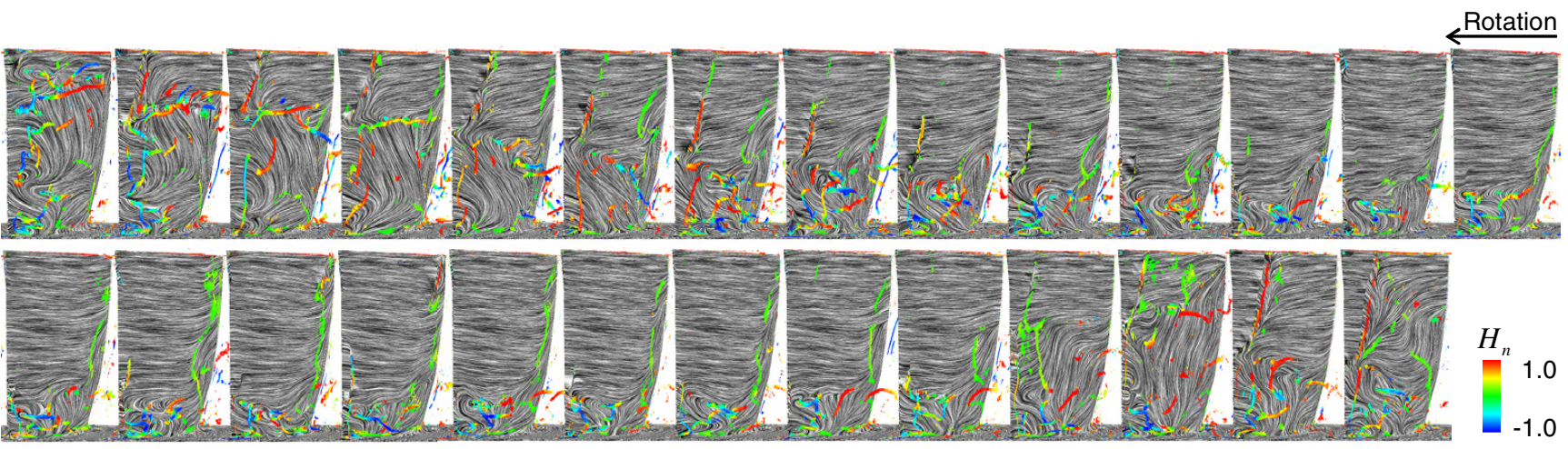

Fig.11 Instantaneous vortical flow structures in 2nd rotor at stalling condition (Front 2-stage simulation, Point III)

effect extends to the upstream 2nd rotor, and the flow angle in the 2nd rotor is increased on the hub side as well. The increase in the inlet flow angle provokes the leading-edge separation in the rotor, which eventually triggers the rotating stall. Actually, the rotating stall appears in the 2nd rotor at Point III as mentioned below.

Figure 9 shows time histories of pressure ratio in each of the rotors and stators at stall inception of Point III. The pressure ratio represents the total pressure ratio for the rotors and the static pressure ratio for the stators, and it is normalized by its pre-stall value at the same operating condition. The pressure ratio has rapidly decreased in the 2 nd rotor after passing around 26 revolutions; namely the stall has started from the 2 nd rotor. The pressure ratio stops decreasing once, but it starts decreasing again and drastically drops within one revolution after 31 revolutions. From the influence of this stall in the 2 nd rotor, the pressure ratio has decreased a little also in upstream and downstream stators at the same time. Regarding the stall which has occurred in the 2 nd rotor, flow phenomena at the stall inception are described below.

Figure 10 shows an instantaneous flow field in the 2nd rotor at the stall inception. This is when the pressure ratio has just started decreasing in the 2nd rotor (Point A in Figure 9; 26.4 revolutions). In the figure, vortex cores and limiting streamlines on the blade suction surface are shown for three rotor pitches. A characteristic event can be seen; there is a separation-type focal point on the limiting streamlines for the center blade of the figure, from which a tornadotype separation vortex has been produced. As mentioned above, the hub corner separation has already happened in the downstream 2nd stator at a little higher massflow rate (Point II) than the stall point (Point III). The blockage effect due to the hub corner separation increases the flow angle of the upstream 2 nd rotor on the hub side, as shown in Figure 8. As a result, the leading-edge separation has been induced in the 2 nd rotor on the hub side, after the corner separation has developed at Point III. As shown in the figure, this leading-edge separation is sometimes released from the blade, generating the tornado-type vortex. This tornado-type separation vortex grows with time, and eventually develops into the rotating stall cell propagating the rotor.

Figure11 shows an instantaneous flow field in 2nd rotor at stalling condition (Point B in Figure9; 31.8 revolutions). In the figure, vortex cores, which are colored with the normalized helicity, and the limiting streamline on the blade suction surfaces are presented. The leading-edge separation is occurring in all blades near the hub, producing complicated large-scale vortices. The hub leading-edge separation is extended to the tip side from the rightside blade to the left-side blade in the upper row, in which the blade loading is lost; this region corresponds to the stall cell. The stall cell occupies about one-third of the annulus. This stall cell rotates in the counter direction to the rotation, propagating in the rotor.

\section{FRONT 7-STAGE SIMULATION}

In this section, the result of the front 7-stage simulation, which includes the 5th and 6th stages suspected of stall initiation, is dis- cussed.

Figure 12 shows a comparison of wall static pressure ratio of each stage at Point A. The pressure ratio is normalized by the design value. The DES is in quite good agreement with the experiment. The calculated pressure ratio is slightly higher in the front stages. Still, the discrepancy is within few points. The pressure ratio is higher than the design value in the 1 st and 2 nd stages, and besides, the 5th and 6th stages. This trend has been successfully predicted by the DES. The trend that the pressure ratio is higher in the 5th and 6th stages also implies that the stall is more likely to happen in those stages.

Figure 13 shows the entropy and Mach number distributions at around $80 \%$ span for an instantaneous flow field at Point A. As regards the Mach number in the the rotor sections, it is presented by the relative value. From the Mach number distribution, the shock waves are found just upstream of the 1st rotor and the 2 nd rotor. The shock wave of the 1st rotor has extended far upstream, interacting with IGV, and its reflecting wave has been propagating inside IGV. In addition, the 1st rotor shock wave has also interacted with the wakes from IGV. Accordingly, the wakes from IGV have been distorted by the interaction. The figure shows that the simulation has succeeded in sharply capturing the shock wave and the wakes.

Figure 14 shows pitchwise-averaged entropy function distribution on the meridional plane at Point A. In the figure, meridional streamlines are presented with black lines as well. The flow field in the figure has been obtained by pitchwise-averaging an instantaneous flow field over full annulus. In the front stages, high entropy is seen near the casing wall owing to the occurrence of strong tip leakage flows and their interaction with the shock wave in the rotors. Especially, the entropy has become higher from the 2 nd rotor tip. As described in the previous section, the stall results from the hub corner stall in the 2nd stator for the front 2-stage simulation. However, such sign is not confirmed in the front 7-stage simulation. Instead, the tip-side flow appears to get into a critical state for the stall in the front stages. For the rear stages, the entropy is generated in the 5th stator (S5 in the figure) on the hub side. This is attributed to the occurrence of hub corner separation, as stated below. In this way, the unfavorable flow phenomenon is already found in the 5th

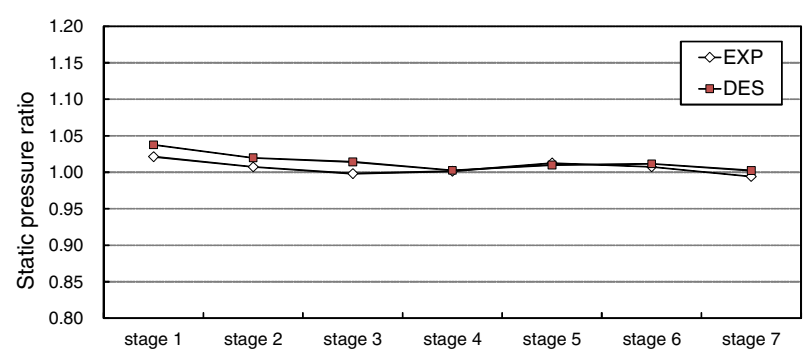

Fig.12 Comparison of stage pressure ratio (Front 7-stage simulation, Point A) 


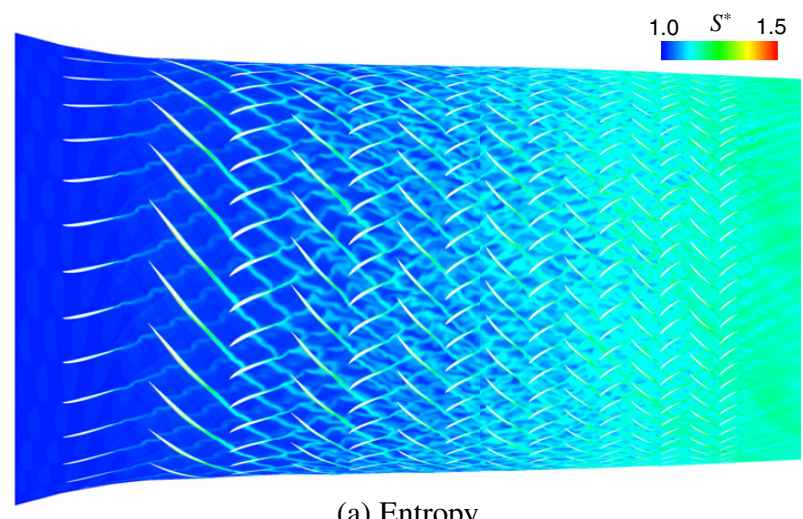

(a) Entropy

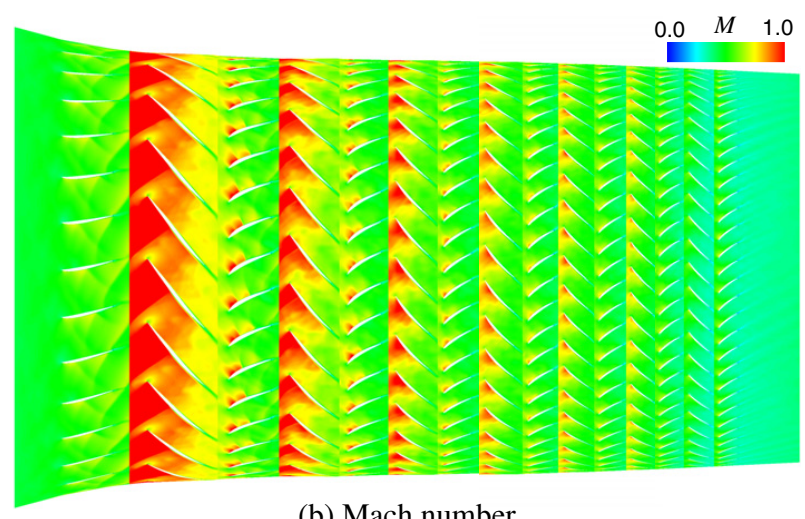

(b) Mach number

Fig.13 Instantaneous flow field naer the casing wall (Front 7-stage simulation, Point A)

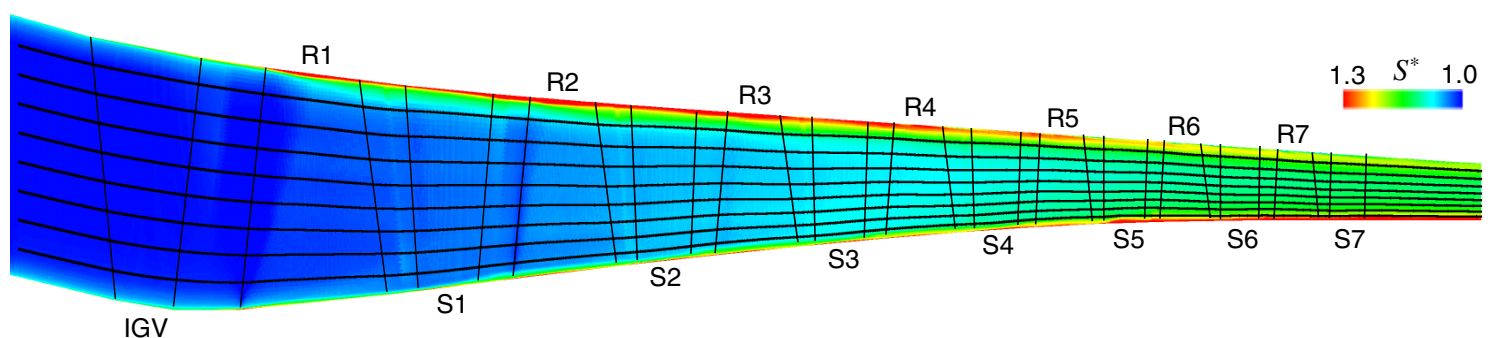

Fig.14 Pitchwise-averaged entropy distribution on meridional plane (Front 7-stage simulation, Point A)

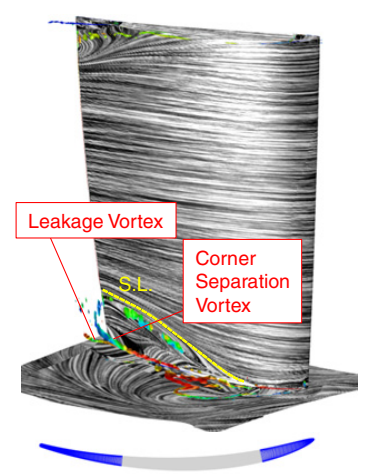

(a) 5th stator

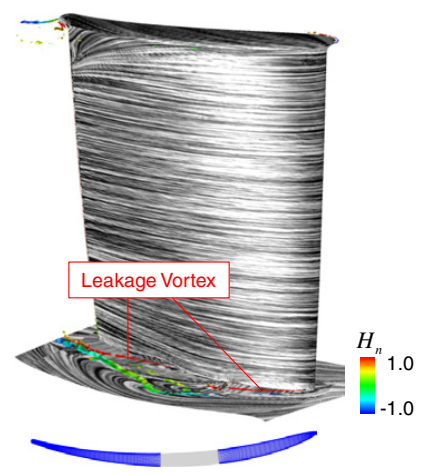

(b) 6th stator
Fig.15 Ensemble-averaged flow fields of 5th and 6th stators (Front 7-stage simulation, Point A)

stator on the hub side prior to the stall, and the rear stages are subject to this hub corner separation in the present compressor. This also suggests that the 5th or 6th stage will be the first stall stage.

Figure 15 shows a comparison of the flow fields between the 5 th stator and the 6th stator. The flow fields presented here in the figure are obtained by ensemble-averaging an instantaneous flow field inside a passage for all passages in the blade row. In the figure, vortex cores and limiting streamlines on the hub and the blade suction surface are shown. As described above, the hub corner separation has arisen in the 5th stator. The reason that the corner separation occurrs in the 5th stator ahead of the 6th stator is related to the clearance size. On the bottom of Figure 15, the partial clearance for each stator is shown with blue color. The partial clearances have been modeled so as to express the real ones, and the partial clearance for the 5th stator is shorter in size in the chordwise direction. This implies that the secondary flow is more likely to develop in the 5th stator thanks to a weak leakage flow. That is why the corner separation comes out in the 5 th stator in first. Low momentum fluids from the hub corner separation in the 5th stator is convected downstream and enters into the subsequent latter stages, which has an unsteady impact on the flow in those stages especially for the

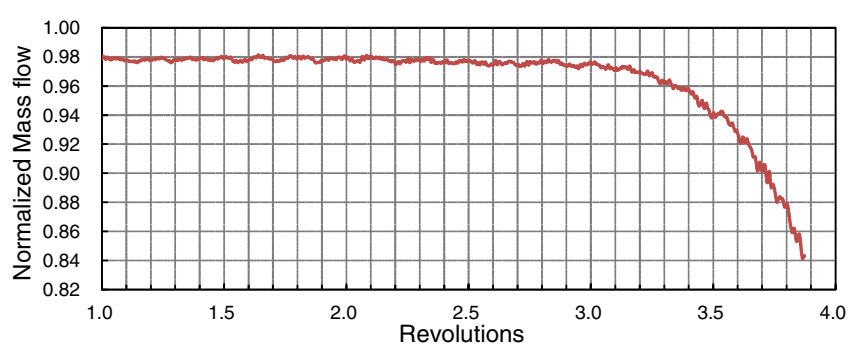

Fig.16 Time history of mass flow (Front 7-stage simulation, Point F)

hub side as described in Figure 14. As a result, the latter stages are also exposed to the danger of the flow separation on the hub side, although its evidence is not confirmed in the figure of the ensembleaveraged flow field.

Next, the unsteady flow phenomena of the stall inception in the front 7 -stage simulation is discussed. Figure 16 shows the time history of mass flow rate at Point $\mathrm{F}$. The abscissa is a non-dimensional time, which is normalized by the rotor rotation period. The simulation at Point $F$ was conducted as a continuation of the simulation at Point $\mathrm{E}$ with a slight increase in the back pressure. More than 15 revolutions have passed in total before the operating point reached Point F. In the figure, the mass flow starts gradually decreasing after the time $t=2.0$, and then it drastically reduces after passing $t=2.8$. This implies that an unsteady flow phenomenon relating to the stall has arisen at around $t=2.0$ and it has developed to the rotating stall by around $t=2.8$. The mass flow decreases with the development of the stall cell.

Figure 17 shows bladerow exit flow fields at the time $t=3.2$ of post-stall for the 5th and 6th stages. The axial velocity distribution on the exit plane is compared. As stated above, the hub corner separation has happened in the 5th stator, so the resultant reversed flow is found on the hub side in all passages. Meanwhile, such reversed flow on the hub side is not almost seen in the 5 th and 6th rotors. For the 6th stator, a reversed flow appears on the hub side in only a part of the passages, and it is larger than that in the 5th stator. This is 


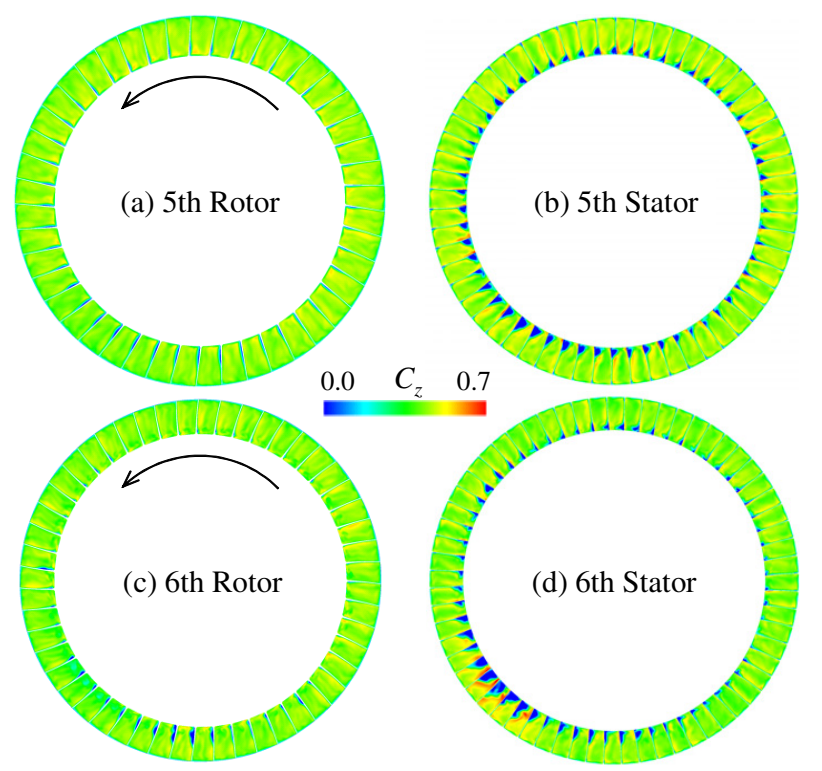

Fig. 17 Comparison of axial velocity distribution on rotor/stator exit planes at $t=3.2$ (Front 7-stage simulation, Point F)
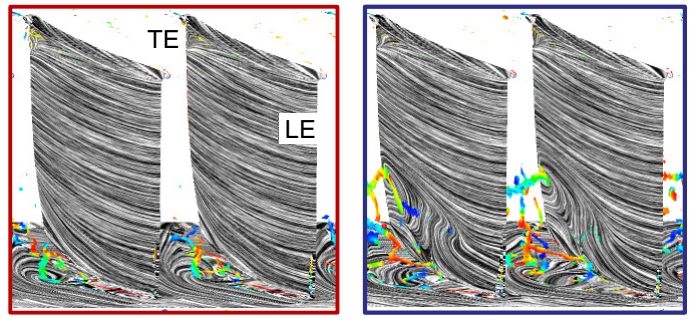

(a) $t=2.2$

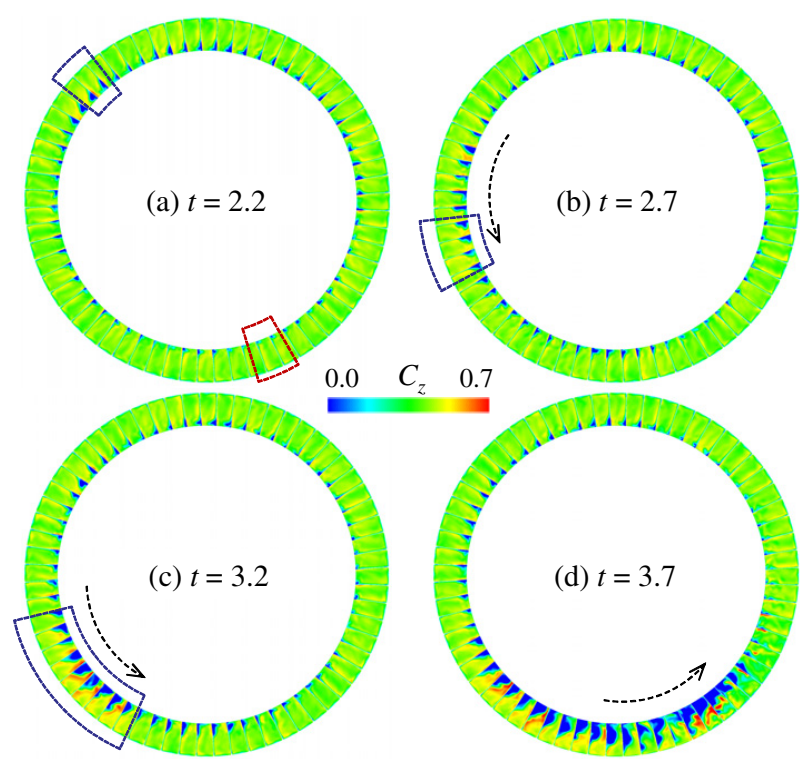

Fig.18 Time variation of axial velocity distribution on 6th stator exit plane (Front 7-stage simulation, Point F)

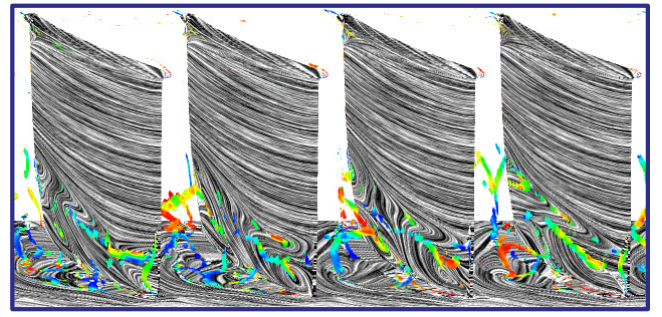

(b) $t=2.7$

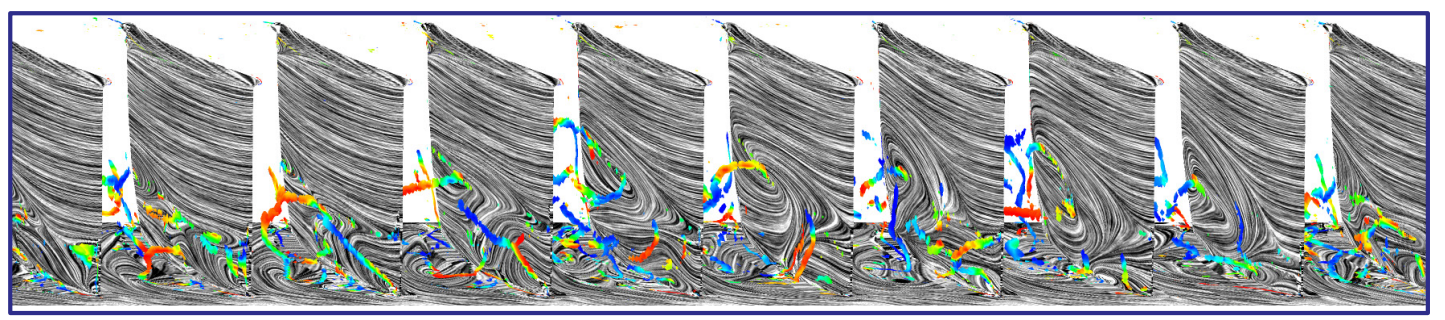

(c) $t=3.2$

Fig.19 Development of rotating stall inception vortex (Front 7-stage simulation, Point F); the internal flow fields corresponding to the region surrounded by a dashed border in Figure 18 are presented by the limiting streamlines and vortex cores

what results from the rotating stall; namely the reversed flow corresponds to the stalled region. The rotating stall happens first in the 6 th stator for the present compressor. At this time, the 2 nd rotor stall has not occurred yet, as described below.

The origination and development of the stall in the 6th stator is illustrated by Figure 18. The figure shows four snapshots of the axial velocity distribution at the 6th stator exit. At $t=2.2$, that is around the time the mass flow was starting to gradually decrease, a small low velocity region is found in all passages on the hub side, but its size is different by passage. In the passages around the blue dashed square, the low velocity region is relatively larger compared to the passages on the opposite side surrounded by the red dashed line. At $t=2.7$, which corresponds to a time just prior to the abrupt decrease in the mass flow, the larger low velocity region has moved to the direction of the rotor rotation with its size developing. As shown in Figure 18(c), the larger low velocity region has drastically developed and it has been distinct, making a group of large low velocity passages. At $t=3.7$, the low velocity region has expanded up to the vicinity of the blade tip. The figure shows that the low velocity region that is the stall cell is propagating in the rotational direction of the rotor, developing in size.

Figure 19 shows the development of the rotating stall inception in the 6th stator and the flow structures inside the stall cell. In the figure, vortical flow structures and limiting streamlines on the blade suction surface and the hub wall are presented for the passages with the stall inception cell, which correspond to the regions surrounded by the blue dashed lines in Figure 18. At $t=2.2$, a large vortical flow structure is found near the hub suction corner. On the limiting streamline, a focal point has appeared near the trailing-edge on the hub side. The hub corner separation happens in a part of passages at this time. At $t=2.7$, the hub corner separation has reached the leading-edge, with the leading-edge separation occurring. Once the leading-edge separation occurs, it rapidly develops into the rotating stall cell, causing the leading-edge separation in the neiboring blades. Therefore, the mass flow drastically decreases with the growth of the stall cell. The figure (c) of $t=3.2$ shows the flow structure inside the stall cell. A tornado-type separation vortex has been generated from the focal point on the blade suction surface in each 


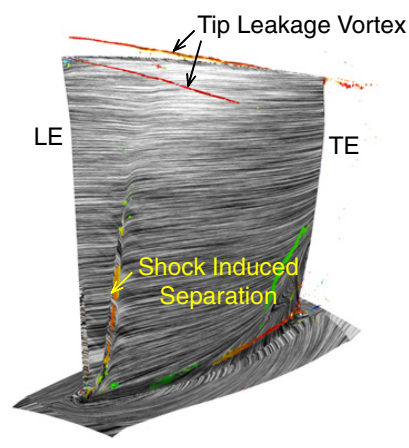

(a) Rotor

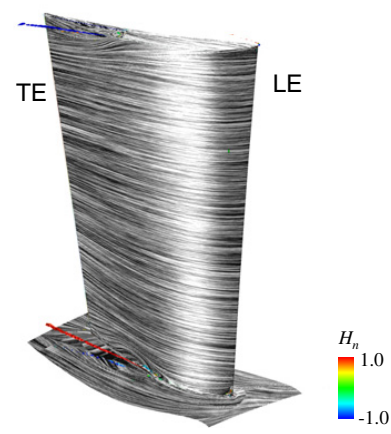

(b) Stator
Fig.20 Ensemble-averaged flow fields of 2nd stage (Front 7-stage simulation, Point E)

passage inside the stall cell. The stall cell consists of these tornadotype separation vortex. The stall cell has expanded not only in the pitch-wise direction but in the span-wise direction. In addition, a large blockage effect due to the stall cell induces the rotating stall in the upstream and downstream bladerows one after another, and finally one large stall cell rotates, spreading over the compressor (figure not shown).

Finally, the flow field in the 2nd stage at Point $\mathrm{E}$ of near-stall point is described. Figure 20 shows vortical flow structures and limiting streamlines in the ensemble-averaged flow field. As shown in the figure, there is no sign of the rotating stall for both rotor and stator; no noticeable flow separation on both tip side and hub side of the blade suction surfaces. In the front 7-stage simulation, the operating point of the 2nd stage is almost unchanged up to Point $\mathrm{E}$ in contrast to the rear stages. Therefore, the flow field in the 2 nd stage remains in a normal state even at Point $\mathrm{E}$, and the stall happens first in the 6th stator prior to the 2 nd rotor stall in the front 7 -stage simulation.

Although both simulations of the front 2-stage and 7-stage show different stall inception and different final form of the rotating stall, they share a common feature of the stall inception in the sense that the stall originates from the hub corner separation. Even in the 2nd rotor of the front stage, the hub corner separation has triggered the stall. The present simulations suggests that the stall can evolve from the separation on the hub side, instead of the leading-edge separation at the tip in the spike stall, as in the present compressor. Also, two types of the stall pattern that originates from the hub corner separation are presented. The result indicates a risk of monitoring only the tip-side flow on the casing wall as stall detection.

\section{CONCLUSIONS}

In order to clarify unsteady flow fields at near-stall condition in a multi-stage axial compressor for an actual industrial gas turbine, large-scale full annulus simulations of the compressor have been conducted using the $\mathrm{K}$ computer. In the present study, two kinds of simulations that are front 2-stage simulation and front 7 -stage simulation have been conducted. The results are summarized as follows.

(1) In the front 2-stage simulation, the hub corner separation occurs in the 2 nd stator at near-stall. The hub corner separation develops with decreasing flow rate, and its blockage effect induces the leading-edge separation in the upstream 2 nd rotor, eventually leading to the rotating stall. The rotating stall cell propagates in the rotor, with the hub leading-edge separation expanding towards the tip, and it occupies about one-third of full annulus.

(2) In the front 7-stage simulation, the hub corner separation appears in the 5th stator already at near-design point because of the small partial clearance. This affects the flow on the hub side in the subsequent 6th stator, and induces the hub corner separation at the stall point and eventually leads to the leading-edge separation on the hub side. The leading-edge separation on the hub side develops into the rotating stall, causing the leadingedge separation in the neiboring blades. Finally, the rotating stall spreads to the upstream and downstream bladerows due to its large blockage effect.

(3) In contrast to the spike stall, the stall starts from the separation on the hub side instead of the leading-edge separation near the tip in the present compressor.

\section{ACKNOWLEDGMENT}

The authors would like to thank Mr. Yoshihiro Hayashi for his assistance with data analysis. This research used computational resources of the K computer provided by the RIKEN Advanced Institute for Computational Science through the HPCI System Research project (Project ID:hp140154).

\section{References}

[1] Day, I. J., 1993, "Stall Inception in Axial Flow Compressors", ASME J. Turbomach., Vol. 115, pp. 1-9.

[2] Garnier, V. H., Epstein, A. H., and Greitzer, E. M., 1991, "Rotating Waves as a Stall Inception Indication in Axial Compressors", ASME J. Turbomach., Vol. 113, pp. 290-301.

[3] McDougall, N. M., Cumpsty, N. A., and Hynes, T. P., 1990, "Stall Inception in Axial Compressors", ASME J. Turbomach., Vol. 112, pp. 116-125.

[4] Hoying, D. A., Tan, C. S., Vo, H. D., and Greitzer, E. M., 1999, "Role of Blade Passage Flow Structures in Axial Compressor Rotating Stall Inception", ASME J. Turbomach., Vol. 121, pp. 735-742.

[5] Vo, H. D., Tan, C. S., and Greitzer, E. M., 2008, "Criteria for Spike Initiated Rotating Stall”, ASME J. Turbomach., Vol. 130, pp. 011023.1-9.

[6] Camp, T. R., and Day, I. J., 1998, "A Study of Spike and Modal Stall Phenomena in a Low-Speed Axial Compressors", ASME J. Turbomach., Vol. 120, pp. 393-401.

[7] Inoue, M., Kuroumaru, M., Tanino, T., Yoshida, S., and Furukawa, M., 2001, "Comparative Studies on Short and Long Length-Scale Stall Cell Propagating in an Axial Compressor Rotor", ASME J. Turbomach., Vol. 123, pp. 24-32.

[8] Inoue, M., Kuroumaru, M., Yoshida, S., and Furukawa, M., 2002, "Short and Long Length-Scale Disturbances Leading to Rotating Stall in an Axial Compressor Stage with Different Stator-Rotor Gaps", ASME J. Turbomach., Vol. 124, pp. 376384.

[9] Young, A., Day, I., and Pullan, G., 2013, "Stall Warning by Blade Pressure Signature Analysis", ASME J. Turbomach., Vol. 135, pp. 011033-1-10.

[10] Weichert, S., and Day, I. J., 2013, "Detailed Measurements of Spike Formation in an Axial Compressor", ASME J. Turbomach., Vol. 136, pp. 051006-9.

[11] Pullan, G., Young, A. M., Day, I. J., Greitzer, E., and Spakovszky, Z., 2015, "Origins and Structure of Spike-Type Rotating Stall”, ASME J. Turbomach., Vol. 137, pp. 051007.

[12] Yamada, K., Kikuta, H., Iwakiri, K., Furukawa, M., and Gunjishima, S., 2013, "An Explanation for Flow Features of SpikeType Stall Inception in an Axial Compressor Rotor", ASME J. Turbomach., Vol. 135, pp. 021023-1-11.

[13] Ikeguchi, T., Matsuoka, A., Sakai, Y., Sakano, Y., and Yoshiura, K., 2012, "Design and Development of a 14-Stage Axial Compressor for Industrial Gas Turbine", Proceedings, ASME Turbo Expo 2012, GT2012-68524. 
[14] Yamada, K., Furukawa, M., Nakano, T., Inoue, M., and Funazaki, K., 2004, "Unsteady Three-Dimensional Flow Phenomena Due to Breakdown of Tip Leakage Vortex in a Transonic Axial Compressor Rotor", Proceedings, ASME Turbo Expo 2004, Paper No. GT2004-53745.

[15] Yamada, K., Funazaki, K., and Furukawa, M., 2007, "The Behavior of Tip Clearance Flow at Near-Stall Condition in a Transonic Axial Compressor Rotor", Proceedings, ASME Turbo Expo 2004, Paper No. GT2007-27725.

[16] Shima, E., and Jounouchi, T., 1997, "Role of CFD in Aeronautical Engineering (No.14) -AUSM Type Upwind Schemes", Proceedings, the 14th NAL Symposium on Aircraft Computational Aerodynamics, National Aerospace Lab., NAL SP-34, pp. 7-12.

[17] Anderson, W. K., Thomas, J. L., and van Leer, B., 1986, "Comparison of Finite Volume Flux Vector Splittings for the Euler Equations", AIAA Journal, Vol. 24, pp. 1453-1460.

[18] Shima, E., 1997, "A Simple Implicit Scheme for Structured/Unstructured CFD (in Japanese)", Proceedings, 29th Fluid Dynamic Conference, pp. 325-328.

[19] Wilcox, D. C., 1994, "Simulation of Transition with a TwoEquation Turbulence Model”, AIAA Journal, Vol. 32, pp. 247255.

[20] Strelets, M., 2001, "Detached Eddy Simulation of Massively Separated Flows", Proceedings, AIAA, Paper 2001-0879.

[21] Bruna, D., and Turner, M. G., 2013, "A Rothalpy Analysis for the Isothermal Boundary Condition at Casing Applied to the Rotor 37 Transonic Axial Flow Compressor", Proceedings, ASME Turbo Expo 2013, GT2013-94595. 